\title{
Effects of coronary artery surgery on left ventricular performance, segmental wall movement, and exertional ischaemia
}

\author{
NIKOLAOS D HAMOURATIDIS, * CLIVE E HANDLER, $\dagger$ ATHANASSIOS PIPILIS, \\ ALFREDO FIANDRA, PHILLIP B DEVERALL, ALAN K YATES
}

From the Department of Cardiology, Guy's Hospital, London

SUMMARY The effects of coronary artery surgery on left ventricular performance were assessed serially by echocardiography and treadmill exercise testing in 54 patients. Patients were assessed one day before operation and again before patients left hospital (mean 10 days after operation) and one month and six months after operation. At the predischarge assessment, 41 (77\%) patients showed new abnormalities of left ventricular segmental wall movement, chiefly anteroseptal hypokinesia with hyperkinesia of the posterolateral segment. Although there were no significant changes in anteroseptal wall thickening after operation, there was a significant increase in posterior wall thickening at all postoperative assessments. The frequency of this abnormality decreased progressively after operation; it persisted in $19(35 \%)$ patients at six months. Left ventricular fractional shortening decreased after operation and at one month was significantly less than before operation. There were no significant changes in left ventricular diastolic diameter during the study. Haemodynamic function during exercise, the duration of exercise, and features of reversible myocardial ischaemia all improved progressively and significantly after coronary artery surgery.

Abnormalities in left ventricular segmental wall movement and thickening commonly develop early after coronary artery surgery but tend to resolve by six months and do not seem to impair left ventricular contractility at rest or exercise performance and haemodynamic function. Recognition of these echocardiographic changes may be clinically important in the assessment of patients after cardiac surgery.

Left ventricular function is an important prognostic factor after coronary artery surgery. ${ }^{12}$ Most studies have reported that coronary artery surgery is effective in relieving angina pectoris, ${ }^{34}$ but its effects on left ventricular function and wall movement are unclear because studies of this aspect give conflicting results. Whereas some investigators noted postoperative improvements in overall left ventricular function, regional wall motion, and ejection fraction,,$^{5-7}$ others found no change or even a deterioration in these variables. ${ }^{8-10}$ Abnormal interventricular septal motion has been reported to be common after open heart surgery ${ }^{11}{ }^{12}$ but the

Requests for reprints to Dr Clive E Handler, Department of Cardiology, Middlesex Hospital, London WIN 8AA.

Present addresses: *Cardiac Department, G Papanikolaou Hospital, Exohi, Thessaloniki, Greece; tDepartment of Cardiology, Middlesex Hospital, London WIN 8AA.

Accepted for publication 4 January 1988 reasons for this and their influence on left ventricular performance during exercise are obscure.

The aims of this study, therefore, were:

(a) To investigate the serial effects of coronary artery surgery on left ventricular performance and segmental wall movement and thickening.

(b) To assess the incidence of new wall movement abnormalities and their potential importance on exercise performance and haemodynamic function.

(c) To examine the relation between new abnormalities of left ventricular wall movement and residual or recurrent exercise induced myocardial ischaemia.

\section{Patients and methods}

We studied 54 patients (50 men and four women, aged 38-72 (mean 53)) admitted for coronary artery surgery. All patients had angina pectoris refractory 
to optimum medical treatment. Nineteen (35\%) patients had not had a myocardial infarction, 32 $(59 \%)$ had had one myocardial infarction, and three $(6 \%)$ had had two myocardial infarctions. Coronary artery disease was defined as a $>50 \%$ reduction in luminal diameter. Thirty $(56 \%)$ had three vessel disease, $18(33 \%)$ had two vessel disease, and six $(11 \%)$ had single vessel disease. Of the 30 patients with three vessel disease, all had saphenous vein grafting and four had internal mammary grafts applied to the left anterior descending coronary artery. Of the 18 patients with two vessel disease, all had saphenous vein grafts and one had an internal mammary graft to the left anterior descending artery. Of the six patients with single vessel disease of the left anterior descending artery, four had internal mammary grafts and two had saphenous vein grafts. These patients were selected from a larger group of patients routinely admitted for coronary artery surgery. The patients included in this study were those who were willing and able to undergo exercise testing and echocardiography before and serially after operation. Six patients were not considered physically fit enough for exercise testing at the predischarge assessment (mean 10 days after operation) and two of these were also not assessed at one month. The numbers of patients investigated at each of the four serial assessments were therefore: 54,48 , 52 , and 54 respectively.

Echocardiography and symptom limited treadmill exercise testing were performed the day before coronary artery surgery and repeated before patients left hospital and one month and six months after operation.

\section{ECHOCARDIOGRAPHY}

The $M$ mode and cross sectional echocardiograms (Hewlett-Packard 77020 AR ultrasonoscope) were performed before exercise testing with the patient supine and in varying degrees of the left lateral decubitus position. Each echocardiographic study included standard views from parasternal, apical, and subcostal transducer positions. The $M$ mode echocardiograms were recorded at a paper speed of $50 \mathrm{~mm} / \mathrm{s}$ and the cross sectional echocardiograms on a $1 / 2$ inch video tape with a VO 5630 Sony videorecorder for redisplaying the images taken. $M$ mode echocardiograms were obtained by recording the left ventricle at the level of the chordae tendineae to measure the short axis dimensions and fractional shortening. Left ventricular cross sectional echocardiographic images were obtained by recording short and long axis scans through the basal, mid-ventricular, and apical regions of the left ventricle and also two and four chamber apical views.

For the purposes of analysis, the left ventricle was divided into nine segments (fig 1). Most segments
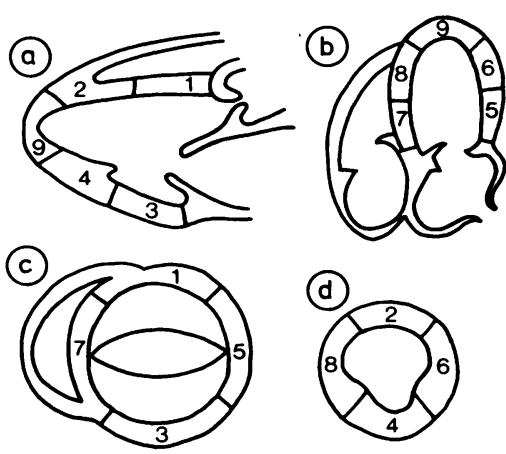

Fig 1 Left ventricular segments derived from echocardiographic views in the (a) long axis parasternal, (b) apical four chamber, (c) parasternal short axis at the level of the mitral valve, and (d) parasternal short axis below the mitral valve cusps.

could be identified from more than one transducer position. The wall movement for each segment was classified and scored as hyperkinetic (score 3), normal (score 2), hypokinetic (score 1), akinetic (score 0 ), and dyskinetic (score -1 ) on the basis of a visual assessment of endocardial movement during systole. Wall thickening in each segment was scored in each segment as normal (score 2$)$, reduced $\left(\geqslant 50^{\circ}{ }_{0}\right.$ reduction in wall thickening compared with normal segments) (score 1), or absent (no systolic thickening or systolic thinning) (score 0 ).

The echocardiograms were scored independently by two observers with a third acting as an arbiter when necessary. The two principal observers agreed completely on the scores on 47 patients. Intraobserver variation measured in a random selection of $\stackrel{\mathbb{D}}{\mathscr{D}}$ echocardiograms was $11^{\circ}{ }_{0}$ and $8^{\circ}{ }_{0}$ for the two observers and this was considered acceptable.

\section{EXERCISE TESTING}

Fasting patients performed a symptom limited exercise test (modified Bruce treadmill protocol). A $12 \mathrm{~J}$ lead electrocardiogram was recorded before exercise and every three minutes during exercise, at peak exercise, at the onset of angina, and every minute $N$ during the five minute recovery period or until the $N$ electrocardiogram trace had returned to its pre-exer-N cise appearance. A three channel rhythm strip was ${ }_{\sigma}^{\omega}$ recorded continuously at a paper speed of $5 \mathrm{~mm} / \mathrm{s}$ for five minutes before and immediately after exercise (with the patient sitting) and throughout the exercise of test. Exercise was stopped if the patient developed severe angina, dyspnoea, fatigue, claudication, dizziness, an abnormal blood pressure response (a fall in $\mathbb{\odot}$ systolic blood pressure of $\geqslant 20 \mathrm{~mm} \mathrm{Hg}$ ), serious $\stackrel{0}{\mathbb{D}}$ ventricular arrhythmias ( $>$ six consecutive ven- $\frac{\circ}{\sigma}$ tricular extrasystoles), or repeated and frequent 
( $>30 /$ minute) ventricular extrasystoles, or $\geqslant 4 \mathrm{~mm}$ of ST segment depression.

\section{DRUGS}

At the preoperative assessment, 46 patients were taking $\beta$ blockers, 48 patients were taking nitrates, and 39 patients were taking a calcium antagonist. At the assessments before leaving hospital and one month after operation no patients were taking any antianginal medication. At the six month exercise test two patients were taking nitrates.

STATISTICAL ANALYSIS

We used analysis of variance for a repeated measures design (to take account of the different numbers of patients at assessments) and the sign test to analyse the exercise test variables. We used Student's paired $t$ test and the $\chi^{2}$ test to compare echocardiographic assessments of left ventricular wall movement and thickening.

\section{Results}

\section{EXERCISE TESTING}

Exertional angina

Exertional angina was significantly $(\mathrm{p}<0.001)$ less common at all three postoperative exercise tests $\left(2^{\circ}{ }_{0}\right.$, $10^{\circ}{ }_{0}$, and $\left.17^{\circ}{ }_{0}\right)$ than preoperatively $\left(65^{\circ}{ }_{0}\right)$.

\section{Exertional $S T$ depression}

Similarly, exertional ST depression (fig 2) at all postoperative assessments $\left(20^{\circ}{ }_{0}, 19^{\circ}{ }_{0}, 24^{\circ}{ }_{0}\right)$ was

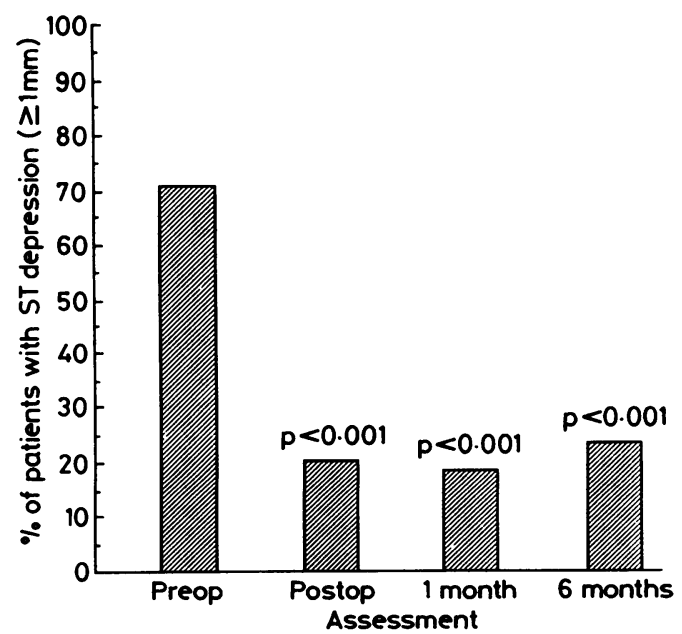

Fig 2 Frequency of $S T$ depression during four serial exercise tests. The p values show the significance of the differences from preoperative values.

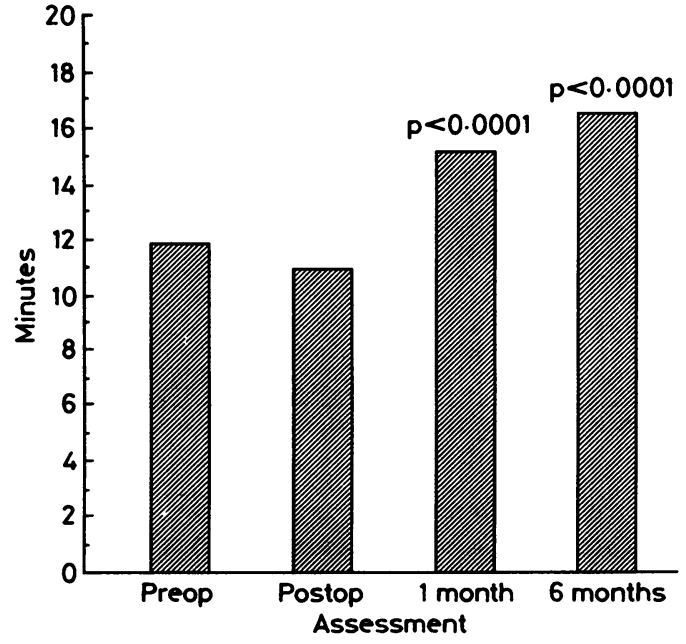

Fig 3 Duration of exercise in minutes at the four serial exercise tests. The $p$ values show the significance of the differences from preoperative values.

significantly less $(p<0.001)$ common than before operation $(71 \%)$.

\section{Exercise duration}

The duration of exercise was slightly shorter during the predischarge test (from 11.9 to 11.0 minutes), but exercise was stopped by leg fatigue and not by angina. At one and six months postoperatively the duration of exercise was significantly increased (from $15 \cdot 2$ to 16.5 minutes, $\mathrm{p}<0.0001$ ) (fig 3 ).

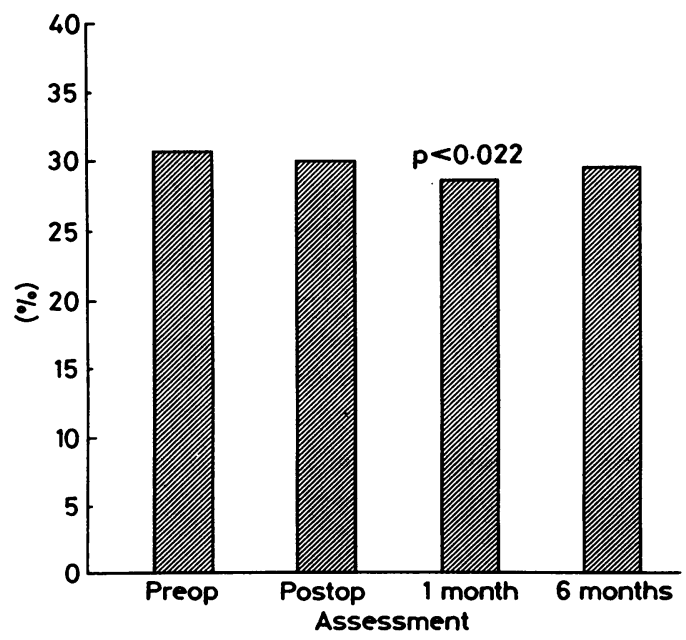

Fig 4 Delta diastolic diameter (left ventricular fractional shortening) at the four serial echocardiographic assessments. The $p$ value shows the significance of the difference from preoperative values. 
Table 1 Abnormalities of segmental wall motion

\begin{tabular}{|c|c|c|c|c|}
\hline & \multirow[b]{2}{*}{$\begin{array}{l}\text { Preop } \\
\text { No }(\%)\end{array}$} & \multicolumn{3}{|c|}{ Postoperative values } \\
\hline & & $\begin{array}{l}\text { Pre- } \\
\text { discharge } \\
\text { No }(\%)\end{array}$ & $\begin{array}{l}1 \text { month } \\
\text { No }(\%)\end{array}$ & $\begin{array}{l}6 \text { months } \\
\text { No }(\%)\end{array}$ \\
\hline $\begin{array}{l}\text { Segments } \\
\text { Hyperkinetic } \\
\text { Normal } \\
\text { Hypokinetic } \\
\text { Akinetic } \\
\text { Dyskinetic }\end{array}$ & $\begin{array}{l}324 \\
9(3) \\
242(76) \\
42(13) \\
24(7) \\
7(2)\end{array}$ & $\begin{array}{l}279 \\
64^{\star}(23) \\
102^{\star}(38) \\
15 \dagger(5) \\
22(8) \\
76^{\star}(27)\end{array}$ & $\begin{array}{l}351 \\
108^{\star}(31) \\
109 \star(31) \\
9 \dagger(3) \\
15(4) \\
110^{\star}(31)\end{array}$ & $\begin{array}{l}342 \\
50^{\star}(15) \\
207(61) \\
17 \dagger(5) \\
16(5) \\
52^{\star}(15)\end{array}$ \\
\hline
\end{tabular}

Comparisons with preoperative values: ${ }^{\star} \mathrm{p}<0.001 ; \nmid \mathrm{p}<0.005$.

Haemodynamic function during exercise

Heart rate at peak exercise rose after operation and at all time points remained higher than preoperative values.

There was also a significant rise in the heart ratesystolic blood pressure double product at peak exercise at all postoperative times.

\section{ECHOCARDIOGRAPHY}

Left ventricular dimensions

Although there were no changes in the short axis left ventricular diastolic diameter ( $M$ mode) during the study, the left ventricular fractional shortening (delta diastolic diameter) showed a slight decrease one month after operation. This was significantly different from the preoperative value $(31.0 \%$ to $28.8 \%, p=0.0216$, fig 4 ).

\section{Segmental wall analysis}

Good quality cross sectional echocardiograms of all segments were obtained in 36 patients before operation, in 31 patients after operation and predischarge, and in 38 and 39 patients at one and six months after operation. There were data for comparative analysis of segmental wall movement and thickening in 26 patients before operation and before discharge after operation; in 30 preoperatively and at one month after operation; in 30 before operation and one month after operation; and in 23 patients before operation $\frac{I}{\Phi}$ and six months after operation.

Tables 1-5 summarise the effects of coronary $c$. artery surgery on segmental wall movement and $\overrightarrow{\vec{F}}$ thickening. Table 1 shows that up to one month after $\stackrel{\mathcal{N}}{+}$ operation there was a significant decrease in the proportion of segments with normal wall movement. $\frac{O}{\bar{N}}$ After operation there was a significant increase in the $\frac{\vec{\sigma}}{\sigma}$ proportion of both dyskinetic and hyperkinetic seg- $\propto$ ments and a significant decrease in the proportion of ${ }_{\omega}$ hypokinetic segments. There was no significant $\vec{\circ}$ change in the proportion of patients with akinetic segments.

Segmental wall movement scores

Scores for anterior and medial wall movement were significantly less up to one month after operation(table 2). Scores for posterior and lateral wall $\mathbb{\omega}_{\tilde{\omega}}$ movement were significantly greater at all post-o operative assessments.

Patients with coexistent abnormalities of anterior and posterior wall movement

The frequency of anteromedial hypokinesia or dys- $\infty_{\infty}^{\infty}$ kinesia or both was significantly greater up to one month after operation. At six months there was noo significant difference. Among these patients, there were parallel and significant increases in the proportion of posterolateral segments that were hyper $-\frac{\alpha}{\phi}$ kinetic.

\section{Segmental wall thickening}

There were no significant changes in the qualitative analysis of segmental wall thickening (table 4). A quantitative analysis, however, showed that there $\vec{\Phi}$

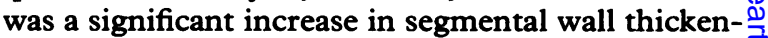
ing during systole in the mid-posterior segment $\overline{0}$ throughout follow up and in the posterobasal segment at six months (table 5).

Postoperative pericardial effusions

At predischarge examination five patients had

Table 2 Mean (SD) segmental wall motion score

\begin{tabular}{|c|c|c|c|c|}
\hline & \multirow[b]{2}{*}{ Preop } & \multicolumn{3}{|c|}{ Postoperative values } \\
\hline & & Predischarge & 1 month & 6 months \\
\hline $\begin{array}{l}\text { Anterobasal } \\
\text { Mid-anterior } \\
\text { Posterobasal } \\
\text { Mid-posterior } \\
\text { Lateral basal } \\
\text { Mid-lateral } \\
\text { Medial basal } \\
\text { Mid-medial } \\
\text { Apical }\end{array}$ & $\begin{array}{l}1.7(0.6) \\
1.5(0.9) \\
1.9(0.4) \\
1.8(0.6) \\
1.9(0.4) \\
1.9(0.6) \\
1.8(0.5) \\
1.5(0.8) \\
1.2(1.1)\end{array}$ & $\begin{array}{c}-0.1(1.2)^{\star} \\
-0.1(1 \cdot 2)^{\star} \\
2.5(0.6)^{\star} \\
2 \cdot 4(0 \cdot 7)^{\star} \\
2 \cdot 5(0 \cdot 6)^{\star} \\
2 \cdot 4(0.6)^{\star} \\
0 \cdot 1(1 \cdot 4)^{\star} \\
0.1(1.4)^{\star} \\
1.0(1.2)\end{array}$ & $\begin{array}{r}0.2(1.3)^{\star} \\
-0.2(1.3)^{\star} \\
2.7(0.4)^{\star} \\
2.6(0.6)^{\star} \\
2.6(0.5)^{\star} \\
2 \cdot 6(0.5)^{\star} \\
-0.1(1.3)^{\star} \\
-0.2(1.3)^{\star} \\
1.3(1.1)^{\star}\end{array}$ & $\begin{array}{l}0.8(1.4) \dagger \\
0.8(1.4) \\
2.3(0.5) \dagger \\
2.3(0.5) \ddagger \\
2.3(0.5) \dagger \\
2.2(0.7) \$ \\
0.9(1.3) \ddagger \\
0.8(1.4) \dagger \\
1.3(1.1)\end{array}$ \\
\hline
\end{tabular}


Table 3 Number of patients with wall motion abnormalities

\begin{tabular}{|c|c|c|c|c|}
\hline & \multirow[b]{2}{*}{$\begin{array}{l}\text { Preop } \\
\text { No }(\%)\end{array}$} & \multicolumn{3}{|c|}{ Postoperative values } \\
\hline & & \multicolumn{2}{|c|}{$\begin{array}{ll}\begin{array}{l}\text { Pre- } \\
\text { discharge }\end{array} & 1 \text { month } \\
\text { No }(\%) & \text { No }(\%)\end{array}$} & $\begin{array}{l}6 \text { months } \\
\text { No }(\%)\end{array}$ \\
\hline $\begin{array}{l}\text { Anteromedial } \\
\text { hypo/dyskinesia } \\
\text { Posterolateral } \\
\text { hyperkinesia }\end{array}$ & $\begin{array}{r}11(30) \\
4(11)\end{array}$ & $24(77)^{\star}$ & $29(74)^{\star}$ & $17(44)$ \\
\hline \multicolumn{5}{|c|}{$\begin{array}{l}\text { Comparisons with preoperative values: }{ }^{\star} p<0.05 ; \nmid p<0.005 \\
\ddagger p<0.001 \text {. }\end{array}$} \\
\hline \multicolumn{5}{|c|}{ Table 4 Segmental wall thickening } \\
\hline & & \multicolumn{3}{|c|}{ Postoperative values } \\
\hline & $\begin{array}{l}\text { Preop } \\
\text { No }\left({ }^{\circ}{ }_{0}\right)\end{array}$ & $\begin{array}{l}\text { Pre- } \\
\text { discharge } \\
\text { No }\left({ }^{\circ}{ }_{0}\right)\end{array}$ & $\begin{array}{l}1 \text { month } \\
\text { No }\left({ }^{o}{ }_{0}\right)\end{array}$ & $\begin{array}{l}6 \text { months } \\
\text { No }\left({ }_{0}{ }_{0}\right)\end{array}$ \\
\hline $\begin{array}{l}\text { Segments studied } \\
\text { Normal thickening }\end{array}$ & $\begin{array}{l}324 \\
250(77)\end{array}$ & $\begin{array}{l}279 \\
206(74)\end{array}$ & $\begin{array}{l}351 \\
288(82)\end{array}$ & $\begin{array}{l}342 \\
290(85)\end{array}$ \\
\hline $\begin{array}{l}\text { Reduced } \\
\text { thickening } \\
\text { No thickening }\end{array}$ & $\begin{array}{l}50(15) \\
24(7)\end{array}$ & $\begin{array}{l}53(19) \\
20(7)\end{array}$ & $\begin{array}{l}46(13) \\
17(5)\end{array}$ & $\begin{array}{l}36(10) \\
16(5)\end{array}$ \\
\hline
\end{tabular}

moderate pericardial effusions that persisted at one month in three. All effusions had resolved completely and spontaneously by six months.

\section{ELECTROCARDIOGRAPHIC CHANGES}

Three patients developed electrocardiographic changes suggestive of perioperative myocardial infarction. One of these patients, who developed new $Q$ waves in the inferior leads, had a normal echocardiogram and electrocardiogram before operation. After operation he developed paradoxical movement of the anterior and medial walls with normal thickening and hyperkinetic posterior and lateral wall movement with slightly reduced posterior wall thickening. The second patient developed reduced $R$ wave progression in the anterior chest leads after operation. Before operation he had apical akinesia and mid-anterior and mid-medial hypokinesia with abnormal thickening of these segments. After operation he developed anterior and medial dyskinesia with posterior and lateral hyperkinesia and deterioration in anterior and medial wall thickening. The third patient developed new $Q$ waves in leads V1-V3. He had a normal echocardiogram before operation but developed paradoxical anterior and medial wall movement and hyperkinetic posterior and lateral wall movement with slightly reduced medial wall thickening at predischarge examination. His echocardiogram reverted to normal by six months.

\section{Discussion}

Coronary artery surgery is generally considered to be effective in relieving angina pectoris, ${ }^{34}$ and the results from our study substantiate this. Features of exercise induced myocardial ischaemia, exercise duration, and haemodynamic function all improved progressively and significantly during the six month follow up. The increases in heart rate and double product after operation may be explained by the withdrawal of $\beta$ blockers. Antianginal medication may mask exercise induced myocardial ischaemia but the frequency of both angina and ST depression decreased significantly after operation indicating effective myocardial revascularisation. Because we did not assess graft patency we did not attempt to correlate segmental wall movement and myocardial blood supply.

The effects of myocardial revascularisation on myocardial function and left ventricular wall movement are controversial. Some workers reported small changes or deteriorations in left ventricular function ${ }^{89}$ and regional contractility, ${ }^{10-12}$ whereas others found improvements in left ventricular performance. ${ }^{5-7}$ The discrepancy between these results may be partially explained by differences in imaging techniques, in the timing of postoperative assessments, ${ }^{210}$ in patency rates for vein grafts, ${ }^{13}$ or in the methods for assessing segmental wall contractility. Some have analysed segmental wall movement by

Table 5 Segmental wall thickening score (mean (SD))

\begin{tabular}{|c|c|c|c|c|}
\hline Segments & Preop & $\begin{array}{l}\text { Predischarge } \\
\text { postop }\end{array}$ & $\begin{array}{l}1 \text { month } \\
\text { postop }\end{array}$ & $\begin{array}{l}6 \text { months } \\
\text { postop }\end{array}$ \\
\hline $\begin{array}{l}\text { Anterobasal } \\
\text { Mid-anterior } \\
\text { Posterobasal } \\
\text { Mid-posterior } \\
\text { Lateral basal } \\
\text { Mid-lateral } \\
\text { Medial basal } \\
\text { Mid-medial } \\
\text { Apical }\end{array}$ & $\begin{array}{l}1.7(0.4) \\
1.5(0.8) \\
1.8(0.4) \\
1.7(0.5) \\
1.9(0.4) \\
1.8(0.5) \\
1.8(0.4) \\
1.6(0.6) \\
1.3(0.9)\end{array}$ & $\begin{array}{l}1.7(0.5) \\
1.4(0.7) \\
1.9(0.3) \\
1.8(0.3)^{\star} \\
1.9(0.3) \\
1.8(0.4) \\
1.7(0.5) \\
1.5(0.7) \\
1.1(0.9)\end{array}$ & $\begin{array}{l}1.8(0.4) \\
1.6(0.6) \\
1.9(0.8) \\
1.9(0.3)^{\star} \\
1.9(0.2) \\
1.9(0.3) \\
1.7(0.5) \\
1.6(0.6) \\
1.4(0.9)\end{array}$ & $\begin{array}{l}1.7(0.5) \\
1.7(0.6) \\
1.9(0.2)^{\star} \\
1.9(0.3)^{\star} \\
1.9(0.2) \\
1.9(0.4) \\
1.8(0.4) \\
1.8(0.4) \\
1.5(0.8)\end{array}$ \\
\hline
\end{tabular}

Comparison with preoperative values: ${ }^{\star} p<0.05$. 
reference to the visual field of the screen, whereas others used the centre of the left ventricular cavity. ${ }^{14}$ It has been suggested that regional wall thickening is more sensitive than regional wall movement for the identification of the extent of the myocardium at risk. ${ }^{15}$ For this reason we analysed regional wall movement and thickening separately.

We found that most wall segments were moving abnormally after operation, especially soon after operation and one month postoperatively. The anterior and medial wall segments moved paradoxically and movement of the posterior and lateral wall was exaggerated. These findings are consistent with previous reports. ${ }^{1012}$ There were no significant abnormalities in left ventricular wall thickening after operation in our patients, but in some patients regional wall thickening, particularly of the posterior wall, was improved. One explanation for this observation is that there was no additional abnormality in segmental wall contractility after coronary artery surgery, but the whole heart moved anteriorly and medially during systole. The mechanism for such segmental wall abnormalities is unclear, but it has been suggested that pericardiotomy may be at least partly responsible. ${ }^{10}$ Occult septal myocardial damage has also been proposed as a cause of this movement abnormality. ${ }^{101216}$ A Venturi effect (caused by the high blood viscosity in the grafts) may reduce blood flow in the septal perforating branches, ${ }^{17}$ but this should also cause abnormal septal wall thickening, which we did not find in our patients.

The decrease in fractional shortening at one month may be related to the pattern of the movement of the heart during systole. Six months after operation there was no significant difference in fractional shortening and most of the abnormalities of segmental wall movement had also resolved.

Bypass-related myocardial damage or ischaemia sufficient to cause an abnormality in wall movement at rest are unlikely mechanisms for the observed wall movement abnormalities in these patients. Perioperative infarction was rare and haemodynamic function during exercise, the duration of exercise, and inducible ischaemia all generally improved rather than deteriorated after coronary operation. Other studies have also reported a significant improvement in the haemodynamic function of the left ventricle in response to stress after coronary artery operation. ${ }^{1819}$

Three of our patients had a perioperative myocardial infarction and all three also developed new abnormalities of wall movement. These were present in most patients soon after operation, and so in isolation they seem to be poor markers of perioperative infarction unless they are accompanied by new abnormalities in wall thickening. ${ }^{20}$
We conclude that new abnormalities in left ven $\frac{T}{D}$ tricular wall movement commonly develop soon aftes coronary artery surgery, but they usually resolve byे six months and do not seem to influence myocardiat. contractility, exercise performance, or haemodyn $\stackrel{\oplus}{\leftrightarrow}$ amic function. Recognition that these changes occup may be clinically useful in the postoperative evalua음. tion of this group of patients.

We thank Dr David Nelson for expert statisticat advice. C E H is grateful to the Medical Research. Council for support during this study.

\section{References}

1 Cohn PF, Gorlin R, Cohn LH, Collins SS. Lefr ventricular ejection fraction as a prognostic guide ip surgical treatment of coronary and valvular heart disease. Am J Cardiol 1974;34:136-41.

2 Bourassa MG, Lesperance J, Campran L, Saltiel SO Fate of left ventricular contraction following aorto coronary venous grafts. Circulation 1972;46:724-30.

3 CASS principal investigators and their associates Coronary Artery Surgery Study (CASS). A randomized trial of coronary artery bypass surgery Circulation 1983;68:951-60.

4 European Coronary Surgery Study Group. Long term results of prospective randomised study of coronar artery bypass surgery in stable angina pectoris. Lance $\underline{t}$ 1982;i:1173-80.

5 Sivertssen E, Sem BG. Left ventricular function afte⿳⺈冂: aortocoronary bypass surgery. Scand J Thorac Car气 diovasc Surg 1979;13:241-8.

6 Kent KM, Borer JS, Green MV, et al. Effects o영 coronary artery bypass on global and regional left ventricular function during exercise. $N$ Engl $J$ Me 1978;298;1434-9.

7 Mintz LJ, Ingels NB, Daughters GT, Stinson EB Alderman EL. Sequential studies of left ventricula function and wall motion after coronary arteriat bypass surgery. Am J Cardiol 1980;45:210-6.

8 Shepherd RL, Itscovitz SB, Glancy DL, et ah Deterioration of myocardial function following aortocoronary bypass operation. Circulation 1974;49:467-75.

9 Arbogast R, Solignac A, Bourassa MG. Influence os aortocoronary saphenous vein bypass surgery on le ventricular volumes and ejection fraction. Am J Menচ $1973 ; 54: 290-6$.

10 Righetti A, Crawford M, O'Rourke R, et al. Interverf tricular septal motion and left ventricular function after coronary bypass surgery. $\mathrm{Am} J$ Cardiof 1977;39:372-7.

11 Ren JF, Panidas I, Kotler MN, et al. Effect of coronar bypass surgery and valve replacement on left verf tricular function assessment by intra-operative twodimensional echocardiography. Am Heart J 1985, 109:281-9.

12 Rubenson DS, Tucker CR, London E, et al. Twä dimensional echocardiographic analysis of segment. left ventricular wall motion before and after coronary 

artery bypass surgery. Circulation 1982;66:1025-33.

13 Steele P, Battock D, Pappas G, Vogel R. Effect of parent coronary arterial occlusion on left ventricular function after aortocoronary bypass surgery. Am J Cardiol 1977;39:39-42.

14 Ribeiro P, Nihoyannopoulos P, Farah S, et al. Role of transient ischaemia and perioperative myocardial infarction in the genesis of new septal wall motion abnormalities after coronary bypass surgery. $\mathrm{Br}$ Heart J 1985;54:140-4.

15 Buda AJ, Zotz RJ, Pace DP, Krause LC. Comparison of two-dimensional echocardiographic wall motion and wall thickening abnormalities in relation to the myocardium at risk. Am Heart J 1986;111:587-92.

16 Akins CW, Boucher CA, Pohost GM. Preservation of interventricular septal function in patients having coronary artery bypass grafts without cardiopulmon- ary bypass [Abstract]. Am J Cardiol 1981;47:394.

17 Lengyel M. Abnormal septal motion after coronary bypass surgery [Letter]. Am J Cardiol 1978;41:619.

18 Bussman WD, Mayer V, Kober G, Kaltenbach $M$. Ventricular function at rest, during straight leg raising and physical exercise before and after aortocoronary bypass surgery. Am J Cardiol 1979;43:488-93.

19 Carroll JD, Hess OM, Hirzel HO, Turina M, Krayenbuehl HP. Left ventricular systolic and diastolic function in coronary artery disease: effects of revascularisation on exercise-induced ischaemia. Circulation 1985;72:119-29.

20 Ribeiro PA, Foale RA, Nihoyannopoulos P, Westaby S, Moss DW, Oakley CM. The value of cross-sectional echocardiography in detecting perioperative myocardial infarction following coronary artery bypass graft surgery. Eur Heart J 1986;7:1053-61. 